\title{
Statin use is associated with reduced mortality in COPD
}

\author{
V. Søyseth, P.H. Brekke, P. Smith and T. Omland
}

ABSTRACT: Patients with chronic obstructive pulmonary disease (COPD) have an increased risk of ischaemic heart disease (IHD). Statins reduce mortality and morbidity in IHD. It has been hypothesised that statin treatment is associated with reduced long-term mortality in patients with COPD.

Using a retrospective cohort design, 854 consecutive patients (mean age 70.8 yrs; $51.5 \%$ female) with a diagnosis of COPD exacerbation were included in the study at discharge from a Norwegian teaching hospital.

Median follow-up was 1.9 yrs, during which 333 patients died. The crude mortality rate per 1,000 person-yrs was 110 in patients treated with statins, and 191 in patients not treated with statins. After adjustment for sex, age, smoking, pulmonary function and comorbidities, the hazard ratio (HR) for statin users versus statin nonusers was 0.57 (95\% confidence interval $0.38-0.87$ ). When subdividing statin users and statin nonusers into groups according to concomitant treatment with inhaled corticosteroids (ICS) the following HRs were found: 0.75 (0.58-0.98) for ICS only; $0.69(0.36-1.3)$ for statins only; and $0.39(0.22-0.67)$ for the combined treatment with statin and ICS compared with no such treatment.

Treatment with statins was associated with improved survival after chronic obstructive pulmonary disease exacerbation, while inhaled corticosteroids appeared to increase the survival benefit associated with statin use.

KEYWORDS: Chronic obstructive pulmonary disease exacerbation, inhaled corticosteroids, mortality, observational study, statin

hronic obstructive pulmonary disease (COPD) is characterised by chronic airflow limitation that is usually progressive [1]. Since the mid 1990s mortality from COPD has increased, and COPD is expected to become the third greatest cause of mortality in Western countries by the year 2020 [2]. The majority of the patients are current or former smokers $[1,3]$. Thus, patients with COPD are likely to develop other smoking-related diseases as well, predominantly symptomatic or asymptomatic ischaemic heart disease (IHD) $[4,5]$.

Chest pain and dyspnoea are the most common symptoms in patients with IHD [6]. The likelihood of these symptoms increases with increasing intensity of exercise. Likewise, patients with COPD frequently experience dyspnoea or even chest pain on exertion or during an exacerbation. Thus, in COPD patients these symptoms may be misinterpreted as COPD-related symptoms even if the origin is cardiac. Moreover, exercise capacity may be limited by impaired lung function concealing the coronary symptoms. Unfortunately, exercise testing and pharmacological stress testing for detection of myocardial ischaemia is often poorly suited for patients with COPD. Hence, IHD among COPD patients may persist undiagnosed even though cardiovascular disease is increasingly being recognised as a leading cause of death in COPD [7].

After an exacerbation of COPD the median survival is only $3-5$ yrs $[8,9]$. The prognosis is particularly serious in patients with hypercapnia and the presence of several comorbidities. Apart from long-term oxygen treatment, which is restricted to patients with chronic respiratory failure, no current therapies for COPD are known to alter long-term prognosis [3]. Whether inhaled corticosteroids (ICS) improve the prognosis is still a matter of controversy [10]. By contrast, several drugs have been shown to improve prognosis after acute coronary events during the last $20 \mathrm{yrs}$, in particular hydroxymethylglutaryl CoA reductase inhibitors (statins) [11].

The current authors hypothesised that many COPD patients might have subclinical IHD and that use of statins might be associated with
AFFILIATIONS

Dept of Medicine and Faculty Division, Akershus University Hospital

Lørenskog, Norway.

CORRESPONDENCE

V. Søyseth

Dept of Medicine and Faculty Division

Akershus University Hospital

N-1478-Lørenskog

Norway

Fax: 4767902125

E-mail: vidar.soyseth@

medisin.uio.no

Received:

August 142006

Accepted after revision:

October 112006

SUPPORT STATEMENT

The authors received financial

support from the Eva Zakariassen

Memorial Fund.

STATEMENT OF INTEREST

Statements of interest for P.H. Brekke and T. Omland can be found at www.erj.ersjournals.com/misc/ statements.shtml 
improved survival. Moreover, whether concurrent use of ICS would modify outcome was also thought to warrant exploration.

\section{METHODS}

\section{Patients and design}

The present study included consecutive patients discharged from Akershus University Hospital (Lorenskog, Norway) from January 1, 2000 through to December 31, 2003 after a COPD exacerbation. Upon discharge from the hospital the diagnosis of each patient was stored in a database using codes from the International Classification of Disease version 10. The patients were selected from this database. The following criteria was used for patient selection: 1) a primary diagnosis of COPD exacerbation with (J44.0) or without lower tract infection (J44.1); or 2) a main diagnosis of pneumonia (J13-J18.9) combined with an unspecified diagnosis of COPD (J44.x). Frequently, it is difficult to decide if COPD exacerbations are accompanied with pneumonia or not. Thus, patients coded with pneumonia as the main diagnosis and COPD as the underlying diagnosis were included. Discharge diagnoses were made by clinical assessment of each patient, and had been verified by a physician specialised in internal medicine or chest medicine. Information on medications, comorbidity, concomitant treatment and smoking history was obtained from the medical records of each patient. No information of compliance of the statin treatment after discharge was available. The patients were considered to have established IHD if: 1) they had a previous diagnosis of myocardial infarction; 2) they had been hospitalised with unstable angina; 3) they had undergone percutaneous coronary intervention; or 4) had coronary artery bypass surgery. Spirometry results in a stable state, i.e. at least 1 week prior to hospitalisation or 1 month after discharge, were available in $72.4 \%$ of the patients. A total of 592 patients had spirometry prior to the current hospitalisation. Among these patients $521(88 \%)$ had a forced expiratory volume in one second to forced vital capacity ratio of $<0.7$. Date of death was obtained from the Central National Register, which is based on a unique personal identification number for all Norwegian inhabitants. Characteristics of the patients at discharge from hospital are shown in table 1.

\section{DATA ANALYSES}

All-cause mortality after discharge from the hospital was used as the outcome measure. First, the age-adjusted relative mortality was assessed using the Mantel-Haenszel test for incidence density data. Secondly, a multivariate analysis was performed using Cox proportional hazards regression. The covariates listed in table 2 were included in the initial multivariate model. If the age-adjusted association between statin use and mortality deviated meaningfully from the ageadjusted mortality of statin, a product-term between the corresponding covariate and statin was included in the initial multivariate model. Backward elimination of covariates was performed if the covariate was not significant and the removal of the covariate did not cause a meaningful change of the association between mortality and treatment with statins. The time after discharge from the hospital was used as the underlying time variable. The proportional hazard assumption was tested using Schoenfeld's residuals on partial likelihood

\begin{tabular}{|c|c|c|c|}
\hline \multirow[t]{3}{*}{ TABLE 1} & of the pati & its at disc & arge from \\
\hline & \multicolumn{2}{|c|}{ Statin user } & \multirow[t]{2}{*}{ Total } \\
\hline & Yes & No & \\
\hline Subjects $n$ & 118 & 736 & 854 \\
\hline \multicolumn{4}{|l|}{ Pneumonia } \\
\hline Yes & $53(44.9)$ & $322(43.8)$ & 375 (43.9) \\
\hline No & $65(55.1)$ & $414(56.3)$ & $479(56.1)$ \\
\hline \multicolumn{4}{|l|}{ Sex } \\
\hline Male & $70(59.3)$ & $344(46.7)$ & $414(48.5)$ \\
\hline Female & $48(40.7)$ & $392(52.1)$ & $440(51.5)$ \\
\hline Age yrs & $68.5 \pm 8.4$ & $71.1 \pm 11.6$ & $70.8 \pm 11.2$ \\
\hline \multicolumn{4}{|l|}{ Spirometry } \\
\hline FVC L & $2.50 \pm 0.81$ & $2.21 \pm 0.83$ & $2.25 \pm 0.83$ \\
\hline FVC \% pred & $77.4 \pm 20.4$ & $71.1 \pm 23.1$ & $72.1 \pm 22.8$ \\
\hline FEV 1 L & $1.36 \pm 0.51$ & $1.16 \pm 0.56$ & $1.19 \pm 0.56$ \\
\hline FEV1 \% pred & $52.4 \pm 16.6$ & $46.7 \pm 20.2$ & $47.6 \pm 19.8$ \\
\hline Spirometry missing & $24(20.3)$ & $212(28.8)$ & $236(27.6)$ \\
\hline \multicolumn{4}{|l|}{ Smoking habits } \\
\hline Never smoker & $10(8.5)$ & $49(6.7)$ & $59(6.9)$ \\
\hline Former smoker & $43(36.4)$ & $277(37.5)$ & $320(37.5)$ \\
\hline Current smoker & $60(50.9)$ & $382(51.9)$ & $442(51.8)$ \\
\hline Missing data & $5(4.2)$ & $28(3.8)$ & $33(3.9)$ \\
\hline \multicolumn{4}{|l|}{ Comorbidity } \\
\hline Lung cancer & $6(5.1)$ & $26(3.5)$ & $32(3.8)$ \\
\hline Cancer at other sites & $7(5.9)$ & $64(8.7)$ & $71(8.3)$ \\
\hline Ischaemic heart disease & $73(61.9)$ & $170(23.1)$ & $243(28.5)$ \\
\hline Congestive heart failure & 29 (24.6) & $140(19.0)$ & $169(19.8)$ \\
\hline Atrial fibrillation & $20(16.7)$ & $147(20.0)$ & $167(19.6)$ \\
\hline Cerebrovascular disease & $16(13.6)$ & $51(6.9)$ & $67(7.9)$ \\
\hline Peripherial vascular disease & $17(14.4)$ & $40(3.0)$ & $28(3.0)$ \\
\hline Arterial hypertension & $44(37.3)$ & $135(18.3)$ & $179(21.1)$ \\
\hline Diabetes & $25(21.2)$ & $77(10.5)$ & $102(11.9)$ \\
\hline Venous thrombembolism & $3(2.5)$ & $18(2.5)$ & $21(2.5)$ \\
\hline \multicolumn{4}{|l|}{ Concomitant treatment } \\
\hline ACEI or ARB & 37 (31.6) & $142(19.3)$ & $179(21.0)$ \\
\hline$\beta$-blockers & $44(37.6)$ & $67(9.1)$ & $111(13.0)$ \\
\hline Acetyl salicylate & $59(50.0)$ & $165(22.5)$ & $224(26.3)$ \\
\hline Warfarin & $16(13.7)$ & $68(9.3)$ & $84(9.9)$ \\
\hline Inhaled corticosteroids & $79(67.0)$ & $462(62.8)$ & $541(63.4)$ \\
\hline Long-term oxygen therapy & $5(4.3)$ & $65(8.9)$ & $70(8.3)$ \\
\hline
\end{tabular}

Data are presented as $n(\%)$ or mean \pm SD, unless otherwise stated. FVC: forced vital capacity; \% pred: \% predicted; FEV 1 : forced expiratory volume in one second; ACEl: angiotensin converting enzyme inhibitor; ARB: angiotensin receptor blocker.

[12]. Results are reported as rate ratio (RR) for stratified analyses or hazard ratio (HR) for Cox analyses, with $95 \%$ confidence intervals $(\mathrm{CI})$ in parentheses.

\section{RESULTS}

The study consisted of 854 patients. The median follow-up was 1.9 yrs. Cumulative survival was $75.4,65.0,59.6$ and $55.6 \%$ at 1 , 2,3 and 4 yrs after discharge, respectively. The crude relative mortality ratio among statin users versus nonusers was 0.58 $(0.39-0.84)$, whereas the age-adjusted relative mortality ratio 


\begin{tabular}{|c|c|c|c|}
\hline \multirow[t]{3}{*}{ TABLE 2} & $\begin{array}{l}\text { aths, m } \\
\text { age-spe }\end{array}$ & $\begin{array}{l}\text { lity rate a } \\
\text { c mortalit }\end{array}$ & $\begin{array}{l}\text { d age- } \\
\text { rate ratio }\end{array}$ \\
\hline & \multicolumn{2}{|c|}{ Statin user } & \multirow[t]{2}{*}{ MRR } \\
\hline & Yes & No & \\
\hline \multicolumn{4}{|l|}{ Sex } \\
\hline Male & $19(121)$ & $160(228)$ & $0.58(0.36-0.94)$ \\
\hline Female & $12(98)$ & $142(162)$ & $0.70(0.38-1.3)$ \\
\hline \multicolumn{4}{|l|}{ Age yrs } \\
\hline$<60$ & $1(17)$ & $25(67)$ & $0.25(0.01-1.6)^{\#}$ \\
\hline $60-69$ & $8(121)$ & $35(97)$ & $1.3(0.50-2.7)^{\#}$ \\
\hline 70-79 & $20(146)$ & $111(202)$ & $0.72(0.43-1.2)^{\#}$ \\
\hline$\geqslant 80$ & $2(105)$ & $131(450)$ & $0.23(0.03-0.86)^{\#}$ \\
\hline \multicolumn{4}{|l|}{ FEV $1 \%$ pred } \\
\hline$<30$ & $5(500)$ & $63(320)$ & $1.5(0.61-3.9)$ \\
\hline $30-49$ & $10(124)$ & $105(214)$ & $0.48(0.25-0.92)$ \\
\hline$\geqslant 50$ & $16(86)$ & $134(150)$ & $0.81(0.42-1.6)$ \\
\hline Missing data & $4(98)$ & $59(167)$ & $0.74(0.27-2.0)$ \\
\hline \multicolumn{4}{|l|}{ Smoking habits } \\
\hline Never smoker & $0(0.0)$ & $18(168)$ & $0.00(0-0.70)$ \\
\hline Former smoker & $18(202)$ & $125(224)$ & $1.2(0.75-2.4)$ \\
\hline Current smoker & $11(75)$ & $149(174)$ & $0.49(0.26-0.91)$ \\
\hline \multicolumn{4}{|l|}{ Comorbidity } \\
\hline Ischaemic heart disease & $20(120)$ & $105(357)$ & $0.43(0.26-0.72)$ \\
\hline Congestive heart failure & $10(156)$ & $99(550)$ & $0.29(0.15-0.55)$ \\
\hline Atrial fibrillation & $8(182)$ & $97(458)$ & $0.52(0.25-1.1)$ \\
\hline Cerebrovascular disease & $4(111)$ & $29(345)$ & $0.36(0.12-1.1)$ \\
\hline Peripherial vascular disease & $6(177)$ & $24(429)$ & $0.43(0.17-1.1)$ \\
\hline Arterial hypertension & $16(172)$ & 55 (194) & $1.1(0.59-2.0)$ \\
\hline Diabetes & $10(208)$ & 49 (395) & $0.81(0.41-1.6)$ \\
\hline Venous thrombembolism & $1(250)$ & $13(650)$ & $1.1(0.19-6.5)$ \\
\hline Lung cancer & $3(375)$ & $21(808)$ & $0.96(0.31-3.0)$ \\
\hline Cancer at other sites & $4(444)$ & $44(579)$ & $0.85(0.29-2.5)$ \\
\hline \multicolumn{4}{|l|}{ Concomitant treatment } \\
\hline ACEI or ARB & $14(194)$ & $71(261)$ & $1.1(0.61-2.1)$ \\
\hline$\beta$-blockers & $11(106)$ & $35(252)$ & $0.57(0.28-1.2)$ \\
\hline Acetyl salicylate & $13(88)$ & 85 (259) & $0.44(0.24-0.82)$ \\
\hline Warfarin & $6(231)$ & $42(362)$ & $0.80(0.32-2.0)$ \\
\hline Inhaled corticosteroids & $19(98)$ & $175(170)$ & $0.65(0.40-1.1)$ \\
\hline Long-term oxygen therapy & $1(91)$ & $37(407)$ & $0.33(0.05-2.1)$ \\
\hline
\end{tabular}

Data are presented as $n$ ( $95 \%$ confidence interval) for MRR, other data are presented as $\mathrm{n}$ (mortality rate $1000^{-1} \cdot \mathrm{yr}^{-1}$ ). FEV1: forced expiratory volume in one second; \% pred: \% predicted; ACEl: angiotensin converting enzyme inhibitor; ARB: angiotensin receptor blocker. ${ }^{\#}$ : age-specific MRR.

was $0.66(0.45-0.96)$. The age-adjusted relative mortality for separate covariates is shown in table 2. Bivariate analyses indicated that the adjusted mortality was lower in statin users than nonusers in almost all the subgroups (table 2). The following covariates were included as product terms with statin in the initial multivariate Cox model: IHD; congestive heart failure; cerebrovascular disease; and treatment with acetyl salicylate. A product term with ICS was also added.

The results of the Cox regression analysis are presented in table 3 . The presence of IHD, congestive heart failure, atrial

\begin{tabular}{|c|c|c|}
\hline Covariate & HR $(95 \% \mathrm{Cl})$ & p-value \\
\hline Sex $\#$ & $0.89(0.70-1.2)$ & 0.4 \\
\hline \multicolumn{3}{|l|}{ Age yrs } \\
\hline$<60$ & 1 & \\
\hline $60-69$ & $1.6(0.93-2.8)$ & 0.09 \\
\hline 70-79 & $2.5(1.5-4.1)$ & $<0.001$ \\
\hline$\geqslant 80$ & $4.5(2.7-7.6)$ & $<0.001$ \\
\hline Current smoking & $1.2(0.89-1.7)$ & 0.2 \\
\hline FEV $1 \%$ pred $+\mathbf{1 0} \%$ & $0.80(0.74-0.86)$ & $<0.001$ \\
\hline \multicolumn{3}{|l|}{ Comorbidity $^{+}$} \\
\hline Ischaemic heart disease & $1.3(1.0-1.7)$ & 0.03 \\
\hline Congestive heart failure & $1.6(1.2-2.2)$ & 0.001 \\
\hline Atrial fibrillation & $1.6(1.2-2.1)$ & 0.002 \\
\hline Diabetes & $1.8(1.3-2.5)$ & $<0.001$ \\
\hline Venous thromboembolism & $2.0(1.0-3.7)$ & 0.04 \\
\hline Lung cancer & $4.6(2.8-7.5)$ & $<0.001$ \\
\hline Cancer other sites & $2.3(1.6-3.3)$ & $<0.001$ \\
\hline \multicolumn{3}{|l|}{ Treatment } \\
\hline Statins & $0.57(0.38-0.87)$ & 0.009 \\
\hline Inhaled corticosteroids & $0.73(0.57-0.94)$ & 0.01 \\
\hline
\end{tabular}

HR: hazard ratio; $\mathrm{Cl}$ : confidence interval; FEV1: forced expiratory volume in one second; \% pred: \% predicted. ${ }^{\#}$ : female versus male; " " yes versus never; ${ }^{+}$: yes versus no.

fibrillation, diabetes, venous thromboembolism, lung cancer, and cancers other than lung cancer, were all associated with increased mortality (table 3). The HR for pneumonia was, however, not higher than in the non-pneumonia group (HR $0.98 ; \mathrm{p}=0.99)$. Moreover, the HR for females was not significantly different from that of males (HR 0.89; $p=0.38$ ), and no significant association between current smoking and mortality was found (HR 1.2; $\mathrm{p}=0.32$ ).

The HR for patients treated with statins was $0.57(0.38-0.87)$ compared with statin non users (table 3 ). None of the product terms between statins and IHD, congestive heart failure, cerebrovascular disease, acetyl salicylate, or ICS were significant $(p=0.20,0.16,0.33,0.57$ and 0.48 , respectively), suggesting no effect modification on statins by any of these covariates. Concomitant treatment with angiotensin converting enzyme inhibitors or angiotensin receptor blockers (HR 1.0 (0.73-1.4)), aspirin (HR $0.94(0.68-1.3)$ ), $\beta$-blockers (HR 0.92 (0.61-1.4)), or warfarin (HR $1.0(0.67-1.6)$ ) did not affect the mortality risk. However, treatment with ICS was associated with improved survival (HR 0.73 (0.57-0.94)).

Finally, statin users and statin nonusers were stratified into ICS users and ICS nonusers. Cox regression analysis, employing the same covariates as in table 3 , revealed that the relative mortality among ICS users only, statin users only, and those using a combination of statins and ICS was 0.75 (95\% CI $0.58-$ $0.98), 0.69$ (95\% CI $0.36-1.3$ ), and 0.39 (95\% CI $0.22-0.67$ ), respectively, compared with patients receiving none of these treatments ( $\mathrm{p}$-trend $<0.001$ ). For the trend test, the coefficients from the corresponding Cox analysis were used as scores. 
The final model did not violate the proportional hazard assumption for any of the covariates or the global test $(\mathrm{p}=$ $0.63)$.

\section{DISCUSSION}

It has been found that the mortality among COPD patients after discharge from hospital was lower among those who were taking a statin compared with those who did not. Furthermore, combined use of statins and ICS was associated with a more favourable prognosis than use of statin alone.

In the present study, nearly $30 \%$ of the patients had diagnosed IHD. Additionally, it is likely that several of the patients had unrecognised IHD. In an autopsy study at the hospital, 106 out of $144(74 \%)$ of the patients with COPD diagnosis had coexisting heart disease [13]. Moreover, in a pilot study of 30 COPD patients hospitalised for exacerbations, 6 patients had an elevated level of troponin T. Three $(50 \%)$ of the patients with elevated troponin $\mathrm{T}$ died 5 months after discharge from the hospital, whereas only one $(4 \%)$ patient died among the remaining 24 patients ( $\mathrm{p}=0.03$; age-adjusted log-rank) [14]. High prevalence of troponin elevation during exacerbation of COPD has also been described previously [15]. Nevertheless, only $12 \%$ of these patients received a diagnosis of acute coronary syndrome. Thus, it appears a considerable proportion of COPD patients may have undiagnosed IHD.

Treatment with statins is now a cornerstone therapy for patients with IHD [11]. A meta-analysis of 90,056 patients in 14 randomised trials showed a $12 \%$ proportional reduction in allcause mortality, and $19 \%$ for coronary and $18 \%$ for respiratory mortality [16]. The latter relationship was, however, not significant. As symptoms of cardiac ischaemia may be misinterpreted as pulmonary symptoms and many COPD patients have too low an exercise capacity to provoke coronary symptoms, it is difficult to identify COPD patients with concomitant IHD. Thus, it appears likely that COPD patients should benefit from statin treatment.

Recently, MANCINI et al. [17] reported that statin treatment reduces mortality among COPD patients in a register-based retrospective cohort study. Interestingly, a decreased number of hospitalisations due to COPD exacerbation was also found. In an experimental study of rat lungs it was found that simvastatin had a suppressing effect on the inflammatory process induced by cigarette smoking [18]. Thus, the beneficial effect of statins may be mediated by an anti-inflammatory effect in the lungs and the airways. In this regard, statin treatment may increase the anti-inflammatory effect on the airways that has been observed with ICS treatment [19]. In the present study there was no effect modification by ICS on the association between statins and mortality, in agreement with MANCINI et al. [17].

There is growing evidence that COPD is associated with a systemic inflammatory component, the intensity of which relates to the severity of the underlying disease [20]. It is conceivable that this systemic component may exacerbate the inflammatory process that is associated with atherosclerosis and atherothrombosis. An association between airways inflammation and cardiovascular events has previously been suggested in studies of the effects of air pollution [21].
There is still controversy concerning a possible survival benefit from long-term use of ICS in COPD. A recent systematic review and meta-analysis found a pooled RR of 0.81 (95\% CI $0.60-1.08)$ for mortality [10]. The present study found that ICS use was associated with reduced mortality, and an additive benefit from concurrent statin use. Even though ICS do not seem to alter the rate of decline in lung function, there is strong evidence that they reduce the frequency of exacerbations, both of which are related to mortality in COPD [22, 23]. A recent observational study by HUIART et al. [24] showed that use of ICS was associated with significant decrease in the risk of myocardial infarction among patients with COPD. Whether ICS can suppress systemic inflammation in COPD is not clear at present, but there are studies suggesting such an effect [25].

The overall mortality rate in the present study was comparable with the long-term mortality rate in previous studies of patients hospitalised with COPD exacerbation [26, 27]. A physician specialised in internal medicine or pulmonary medicine verified the diagnoses. Thus, the study population was well defined. Mortality data were gathered from the Central National Register, which is based on a unique personal identification number for all Norwegian inhabitants. This ensured complete follow-up of the cohort, and makes misclassification of the outcome highly unlikely.

The main limitation of the present study is its nonrandomised design. Thus, statin treatment could have been restricted to patients with inherently better prognosis than patients who were not offered this treatment. Even though many important determinants of mortality were adjusted for in multivariate analyses, the possibility that important prognostic factors might have been imbalanced between the groups cannot be completely ruled out. Moreover, the results should be interpreted with caution due to the limited number of patients. Consequently, the present results should be considered to be hypothesis-generating and not definitive.

In conclusion, the present study shows that use of statins is associated with improved survival after chronic obstructive pulmonary disease exacerbation, regardless of whether or not the patients have a diagnosis of ischaemic heart disease. Concurrent medication with inhaled corticosteroids appears to further enhance this beneficial effect. If these findings can be confirmed in prospective randomised clinical trials, which are now warranted, it may lead to a paradigm shift in the treatment of this large patient population.

\section{ACKNOWLEDGEMENTS}

The authors would like to thank F. Mahmood and LMD. Søyseth for their contribution to data collection from medical records.

\section{REFERENCES}

1 Barnes PJ. Chronic obstructive pulmonary disease. $N$ Eng J Med 2000; 343: 269-280.

2 Murray CJL. Alternative visions of the future: projecting mortality and disability. In: Murray CJL, Lopez AD, eds. The Global Burden of Disease. Harvard, Harvard University Press, 1996; pp. 361-375. 
3 National Institutes of Health, National Heart Lung and Blood Institute. Global strategy for the diagnosis, management, and prevention of chronic obstructive pulmonary disease (GOLD). Publication number 2701. NHLBI/WHO Workshop report, 2001.

4 Hole DJ, Watt GC, Davey-Smith G, Hart CL, Gillis CR, Hawthorne VM. Impaired lung function and mortality risk in men and women: findings from the Renfrew and Paisley prospective population study. BMJ 1996; 313: 711-715.

5 Vollset SE, Tverdal A, Gjessing HK. Smoking and deaths between 40 and 70 years of age in men and women. Ann Intern Med 2006; 144: 381-389.

6 Ganz P, Braunwald E. Coronary blood flow and myocardial ischemia. In: Braunwald E, ed. Heart Disease. 5th Edn. Philadelphia, WB Saunders, 1997; p. 1136.

7 Hansell A, Walk JA, Soriano JB. What do chronic obstructive pulmonary disease patients die from? A multiple cause coding analysis. Eur Respir J 2003; 22: 809-814.

8 Almagro P, Calbo E, de Echagüen AO, et al. Mortality after hospitalization for COPD. Chest 2002; 121: 1441-1448.

9 Soler-Cataluña JJ, Martínez-Garcia MÁ, Román Sánchez P, Salcedo E, Navarro M, Ochando R. Severe acute exacerbations and mortality in patients with chronic obstructive pulmonary disease. Thorax 2005; 60: 925-931.

10 Gartlehner G, Hansen RA, Carson SS, Lohr KN. The efficacy and safety of inhaled corticosteroids in patients with COPD: a systematic review and meta-analysis of health outcomes. Ann Fam Med 2006; 4: 253-262.

11 Smith SC Jr, Allen J, Blair SN, et al. AHA/ACC guidelines for secondary prevention for patients with coronary and other atherosclerotic vascular disease: 2006 update: endorsed by the National Heart, Lung, and Blood Institute. Circulation 2006; 113: 2363-2372.

12 Marubini E, Valsechi MG. Validation of the proportional hazard models. In: Marubini E, Valsechi MG, eds. Analysing Survival Data from Clinical Trials and Observational Studies. Chichester, John Wiley and Sons Ltd, 2004; pp. 223-265.

13 Buajordet I, Ebbesen J, Erikssen J, Brørs O, Hilberg T. Fatal adverse drug events: the paradox of drug treatment. $J$ Intern Med 2001; 250: 327-341.

14 Brekke PH, Omland T, Soyseth V. Myocardial injury in exacerbations of chronic obstructive pulmonary disease (COPD) - a pilot study. Proc Am Thorac Soc 2005; 2: A408.

15 Harvey MG, Hancox RJ. Elevation of cardiac troponins in exacerbation of chronic obstructive pulmonary disease. Emerg Med Australas 2004; 16: 212-215.
16 Baigent C, Keech A, Kearney PM, et al. Efficacy and safety of cholesterol-lowering treatment: prospective metaanalysis of data from 90,056 participants in 14 randomised trials of statins. Lancet 2005; 366: 1267-1278.

17 Mancini GBJ, Etminan M, Zhang B, Brophy JM. Reduction of morbidity and mortality by statins, angiotensinconverting enzyme inhibitors, and angiotensin receptor blockers in patients with chronic obstructive pulmonary disease. J Am Coll Cardiol 2006; 47: 2554-2560.

18 Lee JH, Leen DS, Kim EK, et al. Simvastatin inhibits cigarette smoking-induced enphysema and pulmonary hypertension in rat lungs. Am J Respir Crit Care Med 2005; 172: 987-993.

19 Hattotuwa KL, Gizycki MJ, Ansari TW, Jeffery PK, Barnes NC. The effects of inhaled fluticasone on airway inflammation in chronic obstructive pulmonary disease. A double-blind, placebo-controlled biopsy study. Am J Respir Crit Care Med 2002; 165: 1592-1596.

20 Gan WQ, Man SF, Senthilselvan A, Sin DD. Association between chronic obstructive pulmonary disease and systemic inflammation: a systematic review and a metaanalysis. Thorax 2004; 59: 574-580.

21 Peters A, Dockery DW, Muller JE, Mittleman M. Increased particulate air pollution and the triggering of myocardial infarction. Circulation 2001; 103: 2810-2815.

22 Paggiaro PL, Dahle R, Bakran I, Frith L, Hollingworth K, Efthimiou J. Multicentre randomised placebo-controlled trial of inhaled fluticasone propionate in patients with chronic obstructive pulmonary disease. International COPD Study Group. Lancet 1998; 351: 773-780.

23 Szafranski W, Cukier A, Ramirez A, et al. Efficacy and safety of budesonide/formoterol in the management of chronic obstructive pulmonary disease. Eur Respir J 2003; 21: 74-81.

24 Huiart L, Ernst P, Ranouil X, Suissa S. Low-dose inhaled corticosteroids and the risk of acute myocardial infarction in COPD. Eur Respir J 2005; 25: 634-639.

25 Man SF, Sin DD. Effects of corticosteroids on systemic inflammation in chronic obstructive pulmonary disease. Proc Am Thorac Soc 2005; 2: 78-82.

26 Groenewegen $\mathrm{KH}$, Schols AMWJ, Wouters EFM. Mortality and mortality-related factors after hospitalization for acute exacerbation of COPD. Chest 2003; 124: 459-467.

27 Almagro $\mathrm{P}$, Calbo E, Ochoa de Echagüen $\mathrm{A}$, et al. Mortality after hospitalization for COPD. Chest 2002; 121: 1441-1448. 